\title{
Theoretical and Experimental Investigations on Inclusion Complex $\beta$-Cyclodextrin and Sulcatone: A Cardiovascular Activity Evaluation
}

\author{
Ivan S. Silva, ${ }^{\circledR *, a}$ Eduardo L. Feitosa, ${ }^{a}$ Márcio E. P. Santos, ${ }^{b}$ Raiane M. Silva, ${ }^{a}$ \\ Márcio S. Rocha, ${ }^{a}$ Francisco I. da Silva, ${ }^{c}$ Francisco C. A. Lima, ${ }^{c}$ Ana Maria S. Costa, ${ }^{c}$ \\ Péricles B. Alves, ${ }^{d}$ Samuel A. A. de Sousa, ${ }^{a}$ Aldeídia P. Oliveira ${ }^{b}$ and Sidney G. de Lima ${ }^{\circledR * a}$ \\ ${ }^{a}$ Laboratório de Geoquímica Orgânica, Departamento de Química, Centro de Ciências da Natureza, \\ Universidade Federal do Piauí, Campus Ministro Petrônio Portella, 64049-550 Teresina-PI, Brazil \\ ${ }^{b}$ Centro de Ciências da Saúde, Centro de Pesquisas de Plantas Medicinais, \\ Universidade Federal do Piauí, Campus Ministro Petrônio Portella, 64049-550 Teresina-PI, Brazil \\ 'Laboratório Teórico e Computacional de Química, Departamento de Química, \\ Centro de Ciências Naturais, Universidade Estadual do Piauí, Campus Poeta Torquato Neto, \\ 64002-150 Teresina-PI, Brazil \\ ${ }^{d}$ Departamento de Química, Universidade Federal de Sergipe, Av. Marechal Rondon, s/n, \\ 49100-000 São Cristóvão-SE, Brazil
}

In this paper, we have applied state-of-the-art technologies and new investigations were developed focusing on obtaining simple and inexpensive molecules for treating cardiovascular diseases, as they are considered the leading cause of death in the world. For the first time, the inclusion complex of sulcatone (SU) and $\beta$-cyclodextrin $(\beta-\mathrm{CD})$ was achieved (using a spray drier) and characterized making use of spectroscopic, thermal and computational methods. In addition, the system was evaluated regarding its vasorelaxant properties. Evidence of the inclusion complex formation was provided using different techniques, such as X-ray diffraction (XRD), thermogravimetric analysis (TGA), differential scanning calorimetry (DSC), Fourier transform infrared (FTIR), and ${ }^{1} \mathrm{H}$ nuclear magnetic resonance (NMR) spectroscopies and then deduced by pharmacological experiments, which showed significant changes in relation to the initial material.

Keywords: sulcatone, $\beta$-cyclodextrin, hypotension, vasorelaxant activity, computational methods

\section{Introduction}

In the last years, cardiovascular diseases are the leading cause of death in developed and developing countries, $, 1,2$ causing a great influence on human health, as well as, in social and economic areas. In recent decades, in an effort to decrease this impact, researchers worldwide have been working extensively to make progress in the treatment of cardiovascular diseases including the use of new drugs and therapeutic strategies. ${ }^{3,4}$ Despite enormous advances in research, development and use of natural products as therapeutic agents, detailed understanding on their action mechanisms is lacking. ${ }^{5-8}$ The inclusion of active compounds in the cyclodextrin (CD) cavity may be an

*e-mail: iss.quimica1805@gmail.com; sidney@ufpi.edu.br alternating agent in the formulation of medicines due to the possibility of the drugs-controlled release which present many potential applications. ${ }^{9}$ Studies involving inclusion complexes with cyclodextrins show several advantages, such as the increase of dissolution rate, bioavailability, and reducing toxicity. ${ }^{410}$

Thus, the incorporation of active principles into $\beta-C D$ is a fairly widespread technology. CDs have the ability to form inclusion complexes with a variety of substrates both in solution and in solid phase due to their structure. ${ }^{6}$

This characteristic has led to the application of CDs in most varied areas of industry such as: food, pharmaceutical, cosmetic, biotechnology, analytical chemistry, agriculture and environmental technology. ${ }^{8}$ The commercial viability of oral formulations based on $\mathrm{CD}$ was established with the commercialization of 
more than 20 products worldwide ${ }^{11}$ especially for polar molecules. On the other hand, the use of simple, small and economically viable molecules, although with promising activity (for example: the sulcatone), may have limited use due to their thermal instability, insolubility and bioavailability. Such limitations can be avoided by the inclusion of this CD substance inside.

Therefore, in this work an inclusion complex (IC) of sulcatone (SU) and $\beta$-cyclodextrin were produced using the sprayer drying technique. Theoretical models using computer programs were also performed. Sulcatone (SU) can be found in the essential oil of some citrus plants and has flavoring and allelochemical properties. It is a substance responsible for interspecific communication among individuals of different species. A study published in the journal Nature ${ }^{12}$ showed that sulcatone is an ingredient that differentiates among other odors, being the main reason mosquitoes are attracted to human blood. Thus, the present study aims to prepare and characterize the inclusion complex of sulcatone and $\beta$-cyclodextrin and to evaluate the hypotensive and vasorelaxant activity of this guest molecule.

\section{Experimental}

Material

For our experiments, the following were used: sulcatone (SU), 6-methylhept-5-en-2-one, 98\% (Sigma-Aldrich, St. Louis, MO, USA, molecular weight $\left.=126 \mathrm{~g} \mathrm{~mol}^{-1}\right)$, and $\beta$-cyclodextrin ( $\beta$-CD, Roquette, KLEPTOSE ${ }^{\circledR}$, Lestrem, France, molecular mass $\left.=1134.98 \mathrm{~g} \mathrm{~mol}^{-1}\right)$. The solutions were produced with ultrapure water $(18.2 \mathrm{M} \Omega \mathrm{cm})$ obtained using a Master All (GEHAKA) purification system. The other solvents were all grade PA.

\section{Methods}

\section{Chromatographic conditions}

The identification and quantification analysis of SU were performed using a gas chromatograph (GC) coupled to GCMS-QP2010-SE mass spectrometry (MS) using Rxi-5HT (Resteck) column, with the following dimensions: $30 \mathrm{~m} \times 0.25 \mathrm{~mm} \times 0.25 \mu \mathrm{m}$. Helium was used as carrier gas under a constant flow of $1 \mathrm{~mL} \mathrm{~min}^{-1}$ and the split ratio was 1:100. The oven temperature was maintained at $90{ }^{\circ} \mathrm{C}$ for $1 \mathrm{~min}$, and programmed at a heating rate of $5^{\circ} \mathrm{C} \mathrm{min}-1$ to $110^{\circ} \mathrm{C}$, followed by a second heating ramp of $15{ }^{\circ} \mathrm{C} \mathrm{min}{ }^{-1}$ until the temperature of $150^{\circ} \mathrm{C}$, which was maintained for $5 \mathrm{~min}$. An AOC-5000 self-injector (Shimadzu) was used for injection, and the injection volume was $1 \mu \mathrm{L}$. The mass spectrum of the $\mathrm{SU}$ standard was compared with the mass spectra present in the NIST 10.0 library.

To determine the concentration of SU present in the inclusion complex, an analytical curve was used, which was obtained using the external standard technique based on the integration of the area under the peak curve using the least squares method (standard curve). The standard solution of SU was established at concentration of $1000 \mathrm{mg} \mathrm{L}^{-1}$ in hexane. The curve was constructed from seven solutions diluted in hexane from the standard solution ranging from 100 to $400 \mathrm{mg} \mathrm{L}^{-1}$. Test procedures were performed in triplicate.

\section{Static headspace and gas chromatography (SH-GC) measurements}

The formation constant $\left(\mathrm{K}_{\mathrm{f}}\right)$ for the $\mathrm{SU} / \beta-\mathrm{CD}$ complex was determined using the SH-GC technique. ${ }^{13} 20 \mathrm{mg}$ of SU was weighed directly into six $22 \mathrm{~mL}$ headspace vials. $10 \mathrm{~mL}$ of solutions of different concentrations of $\beta-\mathrm{CD}(0,3,6,9$, $12,15 \mathrm{mM}$ ) were added in each vial. The vials were sealed using silicone septum and aluminum sealing and subjected to shaking at $60 \mathrm{rpm}$ at a temperature of $25 \pm 0.5^{\circ} \mathrm{C}$ for $24 \mathrm{~h}$. After the incubation period, $1 \mathrm{~mL}$ of the vapor was aspirated using an SH-GC (AOC-5000, Shimadzu) automatic sampler and the samples were analyzed by gas chromatography under the conditions described above. These analyses were performed in triplicate.

The value of $K_{f}$ was calculated based on the $A_{0} / A$ ratio of the areas of the SU peaks (according to equation 1), where $\mathrm{A}_{0}$ and $\mathrm{A}$ respectively represent the areas of the peaks in the absence and presence of $\beta-\mathrm{CD}$ and $[\mathrm{CD}]$ the concentration of cyclodextrin. ${ }^{14}$

$\mathrm{K}_{\mathrm{f}}=\frac{\left(\frac{\mathrm{A}_{0}}{\mathrm{~A}}\right)-1}{[\mathrm{CD}]_{0}}$

\section{Preparation of inclusion complex}

The inclusion complex of SU in $\beta-C D$ was prepared according to the method proposed in the literature at a 1:1 molar ratio. ${ }^{15,16} 1.0 \mathrm{~g}$ of SU was solubilized in $25 \mathrm{~mL}$ of ethanol PA and thereafter $9.0 \mathrm{~g}$ of $\beta-\mathrm{CD}$ was solubilized in $250 \mathrm{~mL}$ of ultrapure water heated to $55^{\circ} \mathrm{C}$. After addition of SU to the CD solution, heating was stopped, and the mixture was stirred at $150 \mathrm{rpm}$ for $90 \mathrm{~min}$ at $25^{\circ} \mathrm{C}$. After this period, the solution was subjected to drying with the aid of Mini Spray Dryer B-290 (Buchi) under the following conditions: drying temperature was $105^{\circ} \mathrm{C}$, the spray gas pressure was 0.9 bar and sample flow was $3 \mathrm{~mL} \mathrm{~min}^{-1}$. In 
order to maintain the sample homogeneity during the drying step, the mixture was kept under agitation..$^{17,18}$

\section{Preparation of the physical mixture}

The physical mixture (PM) of SU and $\beta-C D$ was prepared by crunch of $28 \mathrm{mg}$ of SU and $250 \mathrm{mg}$ of $\beta-\mathrm{CD}$ with the support of a mortar with pestle. ${ }^{19}$

\section{Extraction of the hot inclusion complex}

The extraction was performed with $100 \mathrm{mg}$ of the inclusion complex, corresponding to the theoretical mass of $10 \mathrm{mg} \mathrm{SU}$, which was transferred to a headspace vial, resuspended with $4 \mathrm{~mL}$ of ultrapure water. Subsequently, $4 \mathrm{~mL}$ of hexane was added, and the vial was sealed with silicone septum and aluminum seal. The vial was incubated for $15 \mathrm{~min}$ in a water bath maintained at $85{ }^{\circ} \mathrm{C}$, with gentle and intermittent agitation. After the heating period, the solution was kept cooling and the hexane fraction was collected with the help of a glass Pasteur pipette, transferring it to a glass vial. This procedure was repeated two more times and the combined extracts were analyzed by GC-MS.

\section{Efficiency of encapsulation (EE)}

The EE (in \%) was calculated from the determination of the experimental mass of SU present in the inclusion complex, by the equation 2 below:

$$
\mathrm{EE}(\%)=\frac{\mathrm{SU}_{\mathrm{exp}}(\mathrm{mg})}{\mathrm{SU}_{\mathrm{t}}(\mathrm{mg})} \times 100
$$

in which, $\mathrm{SU}_{\exp }$ is the mass of the compound determined in the extraction of the inclusion complex and $\mathrm{SU}_{\mathrm{t}}$ is the theoretical mass used to prepare the inclusion complex.

\section{Fourier transform infrared spectrometry (FTIR) measurements}

The IR spectra of SU, $\beta-\mathrm{CD}, \mathrm{PM}$ and IC were obtained in the median IR region (4000 to $650 \mathrm{~cm}^{-1}$ ) on an Agilent Cary 630 FTIR spectrometer using the ATR technique (attenuated total reflectance). An adequate volume of the sample was positioned directly on the ATR crystal. The IR spectra were smoothed, and the baseline was corrected automatically using the Microlab software.

\section{X-ray diffraction $(\mathrm{XRD})$ measurements}

The analyses were performed on the X-ray diffractometer
PANalytical Empyriam with cobalt anode and Pixel3D collector at Instituto Federal de Educação, Ciência e Tecnologia do Piauí (IFPI). The diffractograms were collected with $\mathrm{Cu} K \alpha$ radiation of $1.54 \AA, 2 \theta$ scan in the range of 10 to $50^{\circ}$ and power from a $40 \mathrm{kV}$ tube and $25 \mathrm{~mA}$ current.

Thermogravimetric analysis (TGA) and differential scanning calorimetry (DSC) measurements

The thermogravimetric analysis (TGA) and differential scanning calorimetry (DSC) analyses were performed on a TGA 2050 (TA Instruments) in an inert nitrogen atmosphere with a flow of $50 \mathrm{~mL} \mathrm{~min}{ }^{-1}$, using a mass of approximately $10 \mathrm{mg}$, wrapped in a hermetically sealed aluminum crucibles. DSC analysis was performed in the range from 30 to $600{ }^{\circ} \mathrm{C}$ and TGA analysis between 30 to $500{ }^{\circ} \mathrm{C}$, under a heating rate of $10{ }^{\circ} \mathrm{C} \mathrm{min}^{-1}$.

${ }^{1} \mathrm{H}$ nuclear magnetic resonance (NMR) spectroscopy measurements

Sulcatone, $\beta$-cyclodextrin and inclusion complex were dissolved in $0.5 \mathrm{~mL}$ of dimethyl sulfoxide (DMSO- $d_{6}$ ). The NMR experiments were recorded at $25{ }^{\circ} \mathrm{C}$ in a Varian INOVA (model 400), operated at $400 \mathrm{MHz}$ for hydrogen. NMR measurements were performed with standard Bruker pulse sequences.

\section{Computational calculations studies}

All the computations have been performed with Gaussian $09,{ }^{20}$ with solvent effect on structural and geometric properties obtained in water, using the polarized continuum model (PCM). The structure of $\beta-C D$ was acquired from the PDB (Protein Data Bank) platform, code-5E6Z, downloaded and adapted to the program UCSF Chimera ${ }^{21}$ and later, molecular optimization calculations were performed with the Gaussian $09,{ }^{20}$ computational package, using the semiempirical method PM6 for the $\beta-\mathrm{CD}$ structure and for the sulcatone structure calculations were performed at the level of functional density theory (DFT), ${ }^{22-24}$ using the method according to Pople and co-workers, ${ }^{25-27}$ M06/6 31g(d), M06/6-31+g(d), M06/6-31+g(d,p), M06/6-311g(d), M06/6-311+g(d) basis set.

As a consequence of these methods being widely used in computational research, the calculations of the sulcatone- $\beta-C D$ inclusion complex were optimized using the ONIOM methodology (M06/6-31g(d):PM6), (M06/6-31+g(d):PM6), (M06/6-31+g(d,p):PM6), (M06/6-311g(d):PM6), (M06/6-311+g(d,p):PM6) basis set $^{28-30}$ in which provided theoretical approximations 
consistent with the experimental values. The results were obtained through the Gauss View 5.0 computational interface. $^{31}$

\section{Cardiovascular effect of sulcatone}

\section{Animals}

Male Wistar rats (Rattus norvegicus), 12-week-old and weighing 250-300 $\mathrm{g}$ each, were obtained from the Bioterium of the Medicinal Plants of the Federal University of Piauí, Brazil, and were used in this study. The animals were maintained in cages at a temperature of $21 \pm 1{ }^{\circ} \mathrm{C}$ in

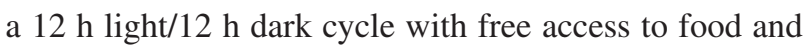
water. All procedures were approved by the UFPI Animal Experimentation Ethics Committee (Protocol/CEEA No. 275/16).

\section{Drugs and reagents}

The composition of Krebs solution (in $\mathrm{mM}$ ) used was: $\mathrm{NaCl}, 158.3 ; \mathrm{KCl}, 4.0 ; \mathrm{CaCl}_{2}, 2.0 ; \mathrm{MgCl}_{2}, 1.05$; $\mathrm{NaH}_{2} \mathrm{PO}_{4}, 0.42 ; \mathrm{NaHCO}_{3}, 10.0$; and glucose, $5.6 \mathrm{mM}$, acetylcholine (ACh), sodium nitroprusside (SNP) (SigmaAldrich, St. Louis, MO, USA), sodium thiopental (Cristália, Itapira, Brazil) and sodium salt of heparin (Roche, Basel, Switzerland). The drugs stock solutions were prepared from dissolution of all substances in distilled water and diluted to the proper concentrations. The sulcatone was dissolved in Krebs solution for the in vitro protocols and brine protocols for in vivo using Cremophor $(0.1 \% \mathrm{v} / \mathrm{v}$, Aldrich, Saint Louis, USA) as the eluent. All solutions were stored at $0{ }^{\circ} \mathrm{C}$.

\section{Experimental procedure for vascular reactivity}

The animals underwent the euthanasia protocol by means of anesthesia overdose $\left(75 \mathrm{mg} \mathrm{kg}^{-1}\right.$, sodium thiopental, intraperitoneal (i.p.)) for the use of the thoracic aorta artery, according to the law statement No. 1000, from May 11, 2012.32 All the protocols were approved by the (Protocol/CEEA No. 275/16).

After euthanasia, an incision was made in the abdominal region. The aorta artery was carefully removed and immersed in a Petri dish containing Krebs solution bubbled with gas mixture $\left(95 \% \mathrm{O}_{2}\right.$ and $\left.5 \% \mathrm{CO}_{2}\right)$. Next, the artery was cleaned of connective and fatty tissues, and was then sectioned into rings from the first segment of the artery (3-4 mm). The rings were individually inserted in stainless steel bands and suspended by cotton threads attached to a tension transducer coupled to an acquisition system (AECAD 1604, AQCAD 2.3.6 software, AVS Projetos, SP) for the recording of isometric contractions. They were kept in tanks containing $6 \mathrm{~mL}$ Krebs $\left(\mathrm{pH} 7.4,37^{\circ} \mathrm{C}, 95 \%\right.$
$\mathrm{O}_{2}$ and $5 \% \mathrm{CO}_{2}$ ). After the assembling of the experiment, each ring was subjected to a constant tension of $1.0 \mathrm{~g} \mathrm{f}^{-1}$ for a 60-min period. During this period, Krebs solution in the tanks was changed every 15 min to avoid the interference of metabolites in the further phases..$^{33}$

After one hour of stabilization, the ring viability was verified with a phenylephrine contraction $\left(10^{-6} \mathrm{M}\right)$, an $\alpha 1$-adrenergic agonist, and the integrity of the vascular endothelium was assessed from the addition of acetylcholine $\left(10^{-6} \mathrm{M}\right)$, an $\mathrm{M}_{3}$ muscarinic agonist. The rings that showed vasorelaxant effect higher than $50 \%$ on the pre-contraction with phenylephrine were considered as endotheliumintact; the rings that showed relaxation lower than $10 \%$ were considered vascular endothelium-denuded; rings with relaxation between 10 and 50\% were discarded from the experiment. ${ }^{34}$ The endothelium-denuded rings, when necessary, were mechanically obtained through the friction between the intimal surface of the vessel and the metal shaft.

The assessment of the vasorelaxant effect of SU was performed after a 60-min period. Both the endotheliumintact and the endothelium-denuded rings were precontracted with phenylephrine $\left(10^{-6} \mathrm{M}\right)$ and there was the cumulative addition of rising concentrations of $\mathrm{SU}$ (0.1-750 $\left.\mu \mathrm{g} \mathrm{mL}^{-1}\right)$ to the tanks in the tonic phase of the contraction for the generation of a concentrationresponse curve. The relaxation was measured through the comparison of the tension developed before and after the addition of sulcatone.

Effect of sulcatone over the arterial pressure and heart rate in rats

These procedures were performed as described by Santos et al..$^{35}$ In summary, for the surgical procedure, the rats were anesthetized with ketamine and xylazine (50 and $5 \mathrm{mg} \mathrm{kg}^{-1}$, respectively) for the insertion of polyethylene catheters. A segment of PE-10 catheter $(4 \mathrm{~cm}$ long, 0.28 and $0.61 \mathrm{~mm}$ inner (i.d.) and outer diameter (o.d.), respectively) was welded to a segment of PE-50 catheter (approximately $15 \mathrm{~cm}$ long, 0.58 and $0.96 \mathrm{~mm}$ i.d. and o.d., respectively). Next, the catheters were inserted in the abdominal aorta, via left femoral artery. After the insertion and attachment with surgical thread, the arterial catheter was filled with heparinized saline solution. It was then tunneled subcutaneously and externalized through an incision in the back cervical region (scapulae) of the animal; the incision was sutured with surgical thread. The measurement of the mean arterial pressure (MAP) was made $24 \mathrm{~h}$ after the surgical procedure by connecting the arterial catheter to a pre-calibrated force transducer (Statham P23 ID; Gould, Cleveland, OH, USA). The 
transducer was coupled to a signal amplifier (Model AVS Projetos, São Paulo, SP, Brazil) connected to a computer equipped with the AQCAD software (AVS Projetos, São Paulo, SP, Brazil) for the analysis. The frequency chosen for the data sampling was $500 \mathrm{~Hz}$. For each cardiac cycle, the computer calculated the systolic, diastolic and mean arterial pressures, as well as the inter-pulse intervals (referred to as cardiac frequency).

On the day of the experiment, after $1 \mathrm{~h}$ of stabilization of the hemodynamic parameters, sodium nitroprusside was administered (10 $\mu \mathrm{g} \mathrm{kg}^{-1}$; intravenous (i.v.)), a nitric oxide donor for the assessment of the proper catheter implantation. After the return to the basal parameters, SU doses were randomly administered $\left(12.5,25\right.$ and $50 \mathrm{mg} \mathrm{kg}^{-1}$, i.v. $)$ in 40 min intervals among the doses. Thus, the effect of SU was observed via intravenous route. For the assessment of the effect of SU via oral route, only the femoral artery was cannulated for the acquisition of the hemodynamic signals. The animals were treated via oral route with saline ( $0.5 \mathrm{~mL} \mathrm{~kg}^{-1}$, control group), $\mathrm{SU}$ (100 $\left.\mathrm{mg} \mathrm{kg}^{-1}\right)$ or $\mathrm{SU}+\beta-\mathrm{CD}\left(100 \mathrm{mg} \mathrm{kg}^{-1}\right), 30 \mathrm{~min}$ after the arterial pressure was recorded. The recordings of the arterial pressure were performed in the first $30 \mathrm{~min}$ up to $240 \mathrm{~min}$.

\section{Statistical data analysis}

All the results were expressed as mean \pm standard error of the mean (SEM). The vasorelaxative potential (pD2) values were obtained by means of non-linear regression. The statistical analysis was carried out with the Student's $t$-test. Values of $p<0.05$ were considered as significant. All the analyses were performed with the GraphPad Prism statistical software. ${ }^{36}$

\section{Results and Discussion}

\section{Sulcatone solubility diagram in $\beta-C D$}

Sulcatone solubility diagram (Figure 1), in $\beta-C D$, presents a linear and ascending profile (AL), suggesting a complexation of sulcatone in $\beta$-CD with a stoichiometry of $1: 1 .^{37} \mathrm{AL}$ type diagrams indicate the formation of soluble complexes.

$\beta$-CD is observed to increase the solubility of SU which is a practically water-insoluble substance. The $\mathrm{K}_{\mathrm{f}}$ value (337.6 $\mathrm{mol} \mathrm{L}^{-1}$ ) was determined by the calculation based on the $\mathrm{A}_{0} / \mathrm{A}$ ratio (equation 1) of the $\mathrm{SU}$ peak areas, where $\mathrm{A}_{0}$ and $\mathrm{A}$ respectively represent the SU peak areas in the absence and in the presence of $\beta-C D$ and $[C D]_{0}$ represents the initial concentration of cyclodextrin. The value obtained for the formation constant of the SU/ $\beta-C D$ complex is

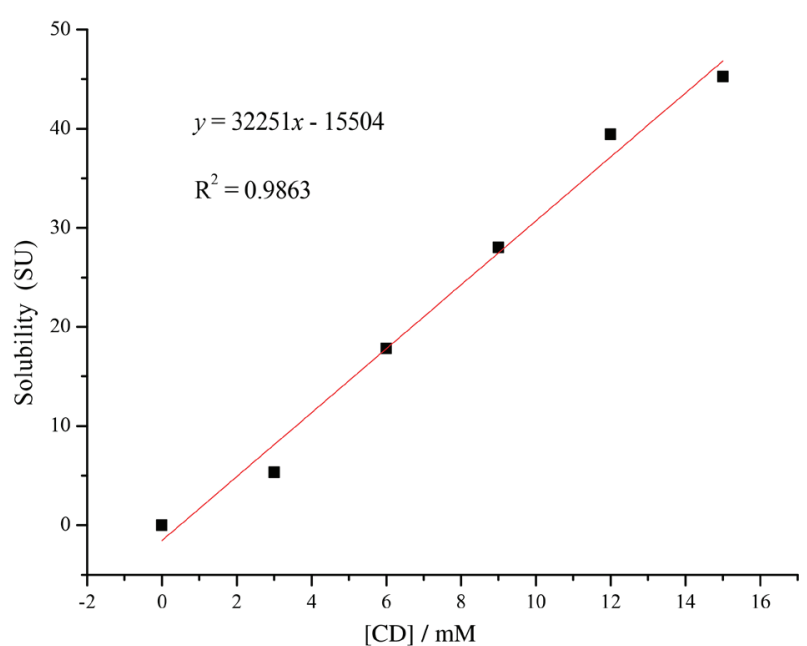

Figure 1. Solubility diagram of sulcatone phases in $\beta-\mathrm{CD}$ indicating complexation stoichiometry $1: 1$.

within the practical range of 200 to $5000 \mathrm{M}^{-1}$ since labile complexes lead to premature release of the guest and very stable complexes result in delayed or incomplete release of the encapsulated molecule. ${ }^{37}$

\section{IC stabilities and extracted sulcatone}

The thermal stability of SU and $\beta-C D$ inclusion complex was performed by headspace and analyzed by GC-MS, as shown in Figure 2.

The samples were incubated at $45^{\circ} \mathrm{C}$ and at the times of 15, 30, 60 and $120 \mathrm{~min}$. The samples were then extracted with hexane to determine the remaining SU. The analysis revealed a relatively low abundance of free $\mathrm{SU}$ at all incubation times at $45^{\circ} \mathrm{C}$, demonstrating the great ability of $\beta-\mathrm{CD}$ to retain or reduce the volatility of $\mathrm{SU}$, contributing to its thermal stability when complexed.

\section{Analytical curve of sulcatone}

The weight yield obtained for the IC of SU and $\beta-C D$ prepared by spray-drying was $65.87 \%$. The literature ${ }^{35}$ reports that the value $36.9 \%$ is acceptable as $\mathrm{m} / \mathrm{m}$ yield in this drying method.

In Figure 3 the linear regression analysis showed a correlation coefficient very close to the unit, $\mathrm{R}^{2}=0.9997$, showing that there is a good linear correlation between two variables $x$ and $y$. After the yield determination, SU present in the IC was extracted and determined, from the analytical curve (Figure 3), that $100 \mathrm{mg}$ of IC has $3.7 \mathrm{mg}$ of SU.

From this information it was possible to calculate the encapsulation efficiency (EE) of the IC resulting in a value of $37 \%$, indicating that out of a total of $10 \mathrm{mg} \mathrm{SU}, 3.7 \mathrm{mg}$ are complexed in the $\beta-\mathrm{CD}$ cavity. 

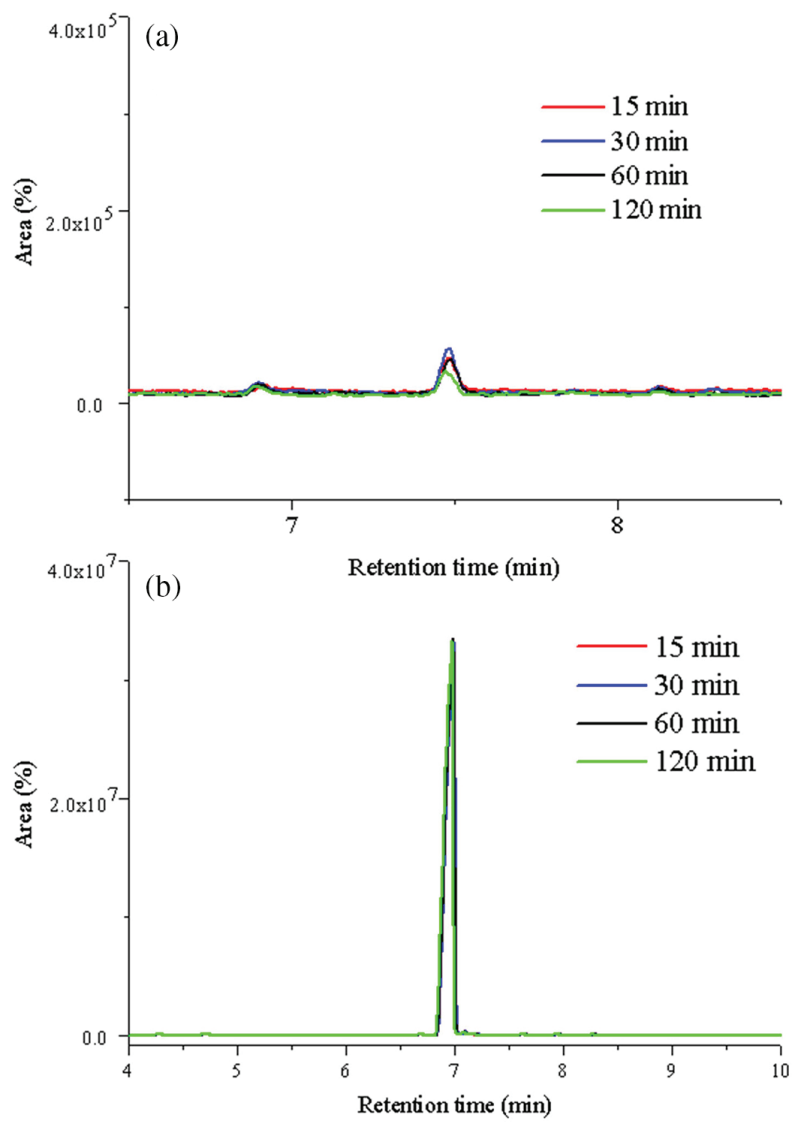

Figure 2. SU IC chromatographic profiles on $\beta$-CD at different incubation times headspace (a) and extracted SU (b).

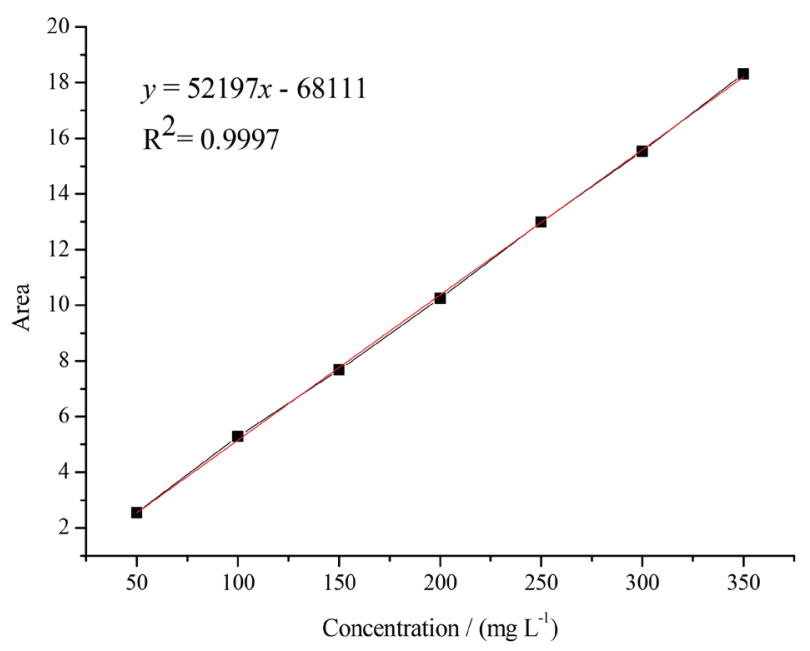

Figure 3. Analytical curve of sulcatone in hexane with concentrations of $100,150,200,250,300,350$ and $400 \mathrm{mg} \mathrm{L}^{-1}$.

\section{FTIR spectroscopy analysis}

The Fourier transform medium infrared spectra of the sulcatone, inclusion complex, $\beta-\mathrm{CD}$ and physical mixture were obtained by the ATR mode and they are displayed in Figure 4.

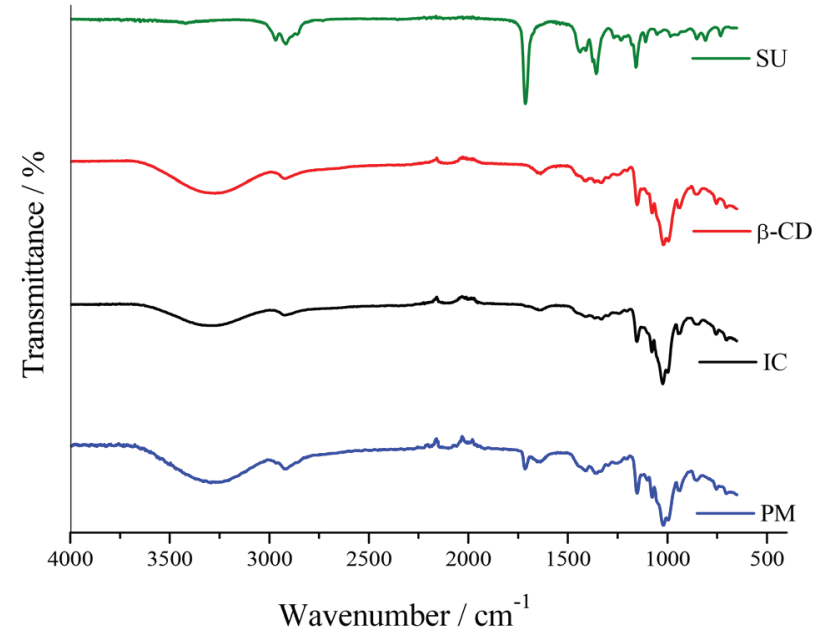

Figure 4. Top-down IR spectra (ATR): sulcatone (SU), $\beta$-cyclodextrin $(\beta-\mathrm{CD})$, inclusion complex (IC), physical mixture (PM).

The absorption bands characteristic of CDs, which represent most of the absorption bands of the inclusion complexes, are little affected by the complexation. The bands related to the guest molecules show deviations to greater or lesser values, accompanied by a decrease in intensity and, in some cases, disappear completely. ${ }^{38}$

In the sulcatone IR spectrum (Figure 4), the absorption bands at 2989 and $2925 \mathrm{~cm}^{-1}$ are attributed to the axial deformation of $\mathrm{C}-\mathrm{H}$ stretching. The band at $1717 \mathrm{~cm}^{-1}$ refers to the normal axial deformation of $\mathrm{C}=\mathrm{O}$, one of the most characteristic features of IR region spectroscopy. The signals of 1455 and $1350 \mathrm{~cm}^{-1}$ are related to the angular deformations in the symmetrical and asymmetrical $\mathrm{C}-\mathrm{H}$ plane, respectively. The band at $1140 \mathrm{~cm}^{-1}$ refers to the axial and angular deformations of the $\mathrm{C}-\mathrm{O}-\mathrm{C}$ system. The $\beta$-CD spectrum shows an intense band at $3314 \mathrm{~cm}^{-1}$ of the axial deformation of $\mathrm{O}-\mathrm{H}$ at the intermolecular hydrogen bond. The signal at $2915 \mathrm{~cm}^{-1}$ refers to the axial deformation of $\mathrm{C}-\mathrm{H}$. The $\mathrm{C}-\mathrm{O}$ stretching of the $\mathrm{COOH}$ system occurred at $1160 \mathrm{~cm}^{-1}$. The absorption band at $1023 \mathrm{~cm}^{-1}$ is attributed to the coupling of the axial C-C and angular deformations of $\mathrm{O}-\mathrm{C}-\mathrm{H}$ and $\mathrm{C}-\mathrm{C}-\mathrm{H}$. In the inclusion complex the $3282 \mathrm{~cm}^{-1}$ stretch band of $\mathrm{O}-\mathrm{H}$ suffered significant deviation, and also the disappearance of the $1664 \mathrm{~cm}^{-1}$ carbonyl $(\mathrm{C}=\mathrm{O})$ band from the $\mathrm{SU}$ shows the encapsulation of this molecule in the $\beta-C D$ cavity, since this signal occurs only in the guest molecule. The encapsulation of a host molecule in the cavity of a cyclodextrin restricts its flexions and vibrations, fact that explain the disappearance of the band at $1140 \mathrm{~cm}^{-1}$. In the physical mixture the main absorption bands of $\beta-C D$ (3314 and $2925 \mathrm{~cm}^{-1}$ ) and sulcatone $\left(1717 \mathrm{~cm}^{-1}\right)$ were maintained, suggesting that the formation of inclusion complex by simple crunch is less favored..$^{37}$ 


\section{X-ray diffraction $(\mathrm{XRD})$ analysis}

Sulcatone is a liquid substance, thus it does not present an $\mathrm{X}$-ray diffraction profile. The phenomenon of complexation is associated with the increased degree of amorphization of the substances involved in the formation of a complex in the solid phase. The $\beta$-CD shows a crystalline structure that was evidenced by the presence of $10^{\circ}$ and $41^{\circ}$ peaks on its diffractogram, as illustrated in Figure 5.

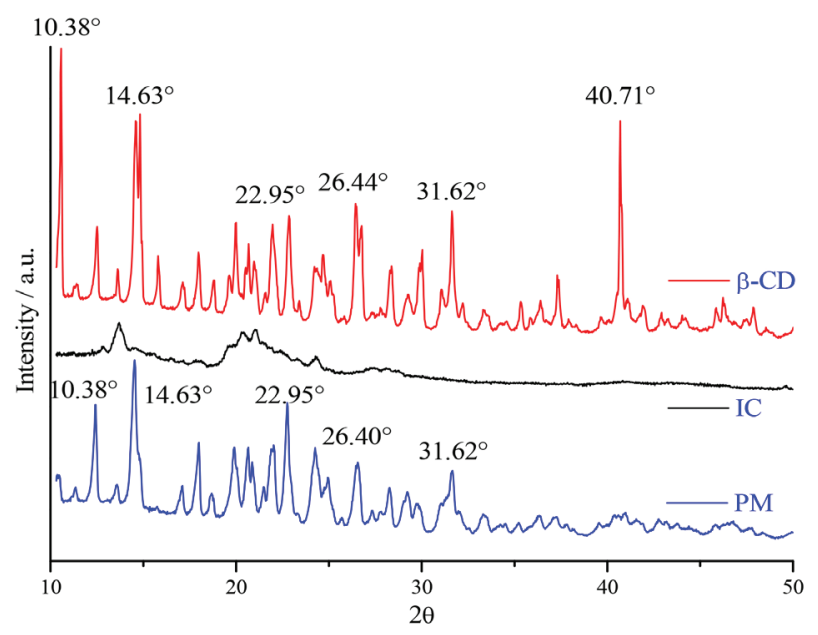

Figure 5. $\beta$-CD diffractograms, inclusion complex (IC) and physical mixture (PM).

As it can be noted in Figure 5, the main XRD peaks presented intensities: 10.38, 14.63, 22.95, 26.44, 31.62 and $40.71^{\circ}$, and this diffraction pattern was confirmed by literature. ${ }^{39}$ The inclusion complex did not show peaks that characterize a crystalline structure, a fact that can be attributed to the presence of sulcatone that increased the degree of the system amorphization. The reduction of the intensities of the principal peaks on the diffractogram (Figure 5) of the physical mixture reveals interactions between sulcatone and $\beta-\mathrm{CD}$ in a less pronounced way than in the inclusion complex. ${ }^{38}$

\section{Differential scanning calorimetry (DSC) analysis}

One of the most used methods in the physicochemical characterization of complexes in the solid phase is the DSC, due to the occurrence of interactions between the guest and the CD, the DSC curves shall present a not coincident profile with the sum of the effects observed in the thermograms of the constituents, ${ }^{39}$ as shown in Figure 6.

As it can be observed in Figure 6, the endothermic peaks at 126 and $302{ }^{\circ} \mathrm{C}$ in the $\beta$-CD thermogram correspond to the events of water loss and cyclodextrin decomposition, respectively. The disappearance of the dehydration peak in

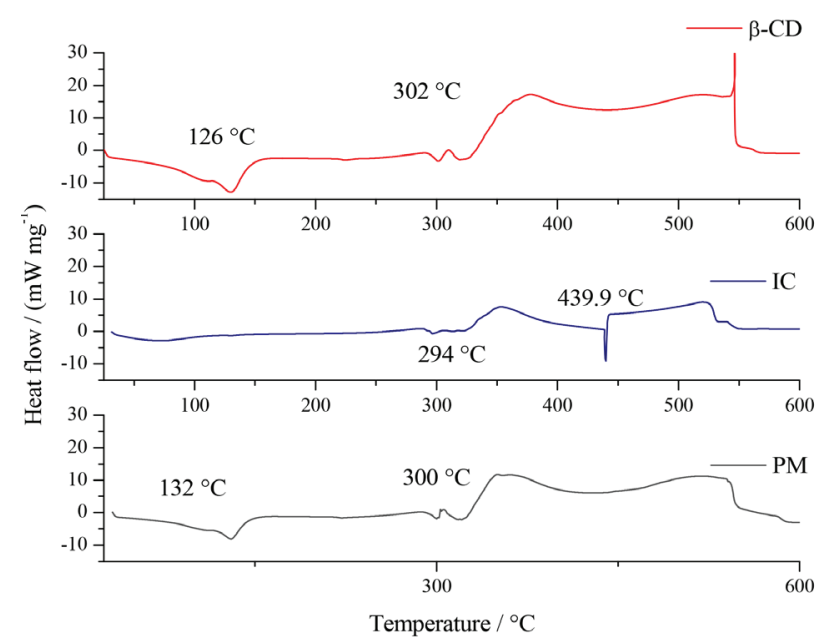

Figure 6. DSC thermograms for $\beta-C D$, inclusion complex (IC) and physical mixture (PM).

the thermogram of the inclusion complex can be explained by the fact that the host molecule (SU) occupies the place of the water in the $\beta$-CD cavity. In this thermogram the thermal event at $439.9{ }^{\circ} \mathrm{C}$ can be attributed to the presence of impurities. Moreover, the physical mixture curve, as illustrated in Figure 6, have the presence of the DSC peaks at 132 and $300{ }^{\circ} \mathrm{C}$ due to dehydration and thermal degradation of $\beta-\mathrm{CD}$, respectively. These changes are justified by the inclusion of a guest molecule in the cyclodextrin cavity causing changes in its melting, boiling or sublimation points prior to the $\mathrm{CD}$ decomposition. ${ }^{40-42}$

\section{TGA analysis}

This technique allows determining the mass losses of the compounds when subjected to heating. ${ }^{37}$ Derived thermogravimetry (DTG) records the rate of mass alteration due to the increase in temperature.

The sulcatone curve (Figure 7a) shows an accentuated loss of mass to a minimum of $15 \%$ at $59{ }^{\circ} \mathrm{C}$ which can be attributed to the high volatility of sulcatone.

The thermograms of the $\beta-C D$ and inclusion complex (Figures $7 \mathrm{~b}$ and $7 \mathrm{c}$ ) show the peak corresponding to $\beta$-CD decomposition. It is observed that the endothermic peak of sulcatone at $59{ }^{\circ} \mathrm{C}$ disappeared because of its inclusion in the cyclodextrin cavity. The thermogram shown in Figure $7 \mathrm{~d}$ bears a strong resemblance to that of $\beta-C D$, highlighting the fact that in physical mixing the complexation is incipient. ${ }^{42}$

\section{${ }^{1} \mathrm{H}$ NMR spectroscopy}

${ }^{1} \mathrm{H}$ NMR techniques provide important information about the structure and interactions established between 

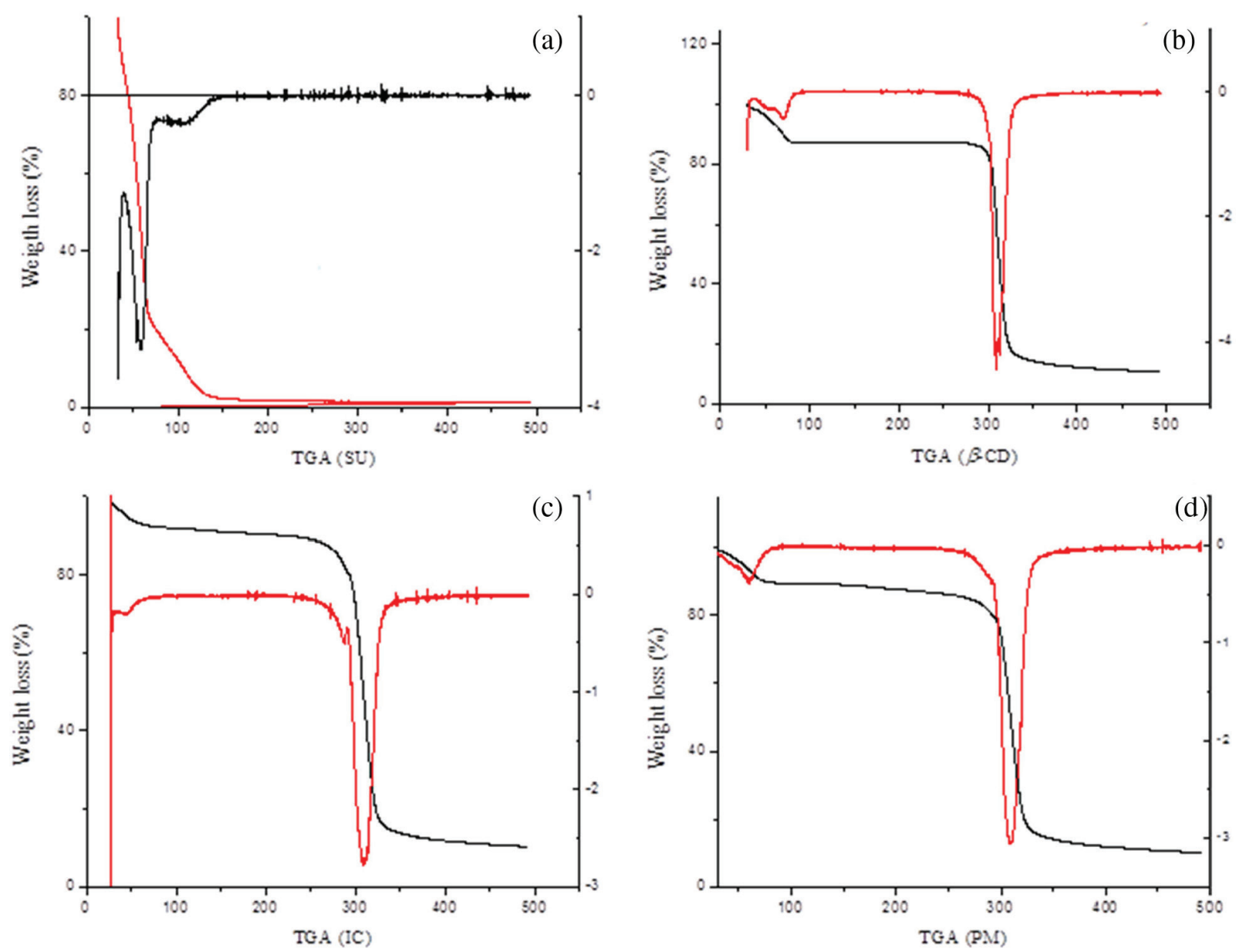

Figure 7. TGA for sulcatone (a); $\beta$-cyclodextrin (b); inclusion complex (c) and physical mixture (d).

the guest molecule and CD. Figure 8 shows the ${ }^{1} \mathrm{H}$ NMR spectra of the free $\beta-C D$ (Figure $8 \mathrm{a}$ ) and the inclusion complex (Figure 8b).

The ${ }^{1} \mathrm{H}$ NMR chemical shifts of $\beta-\mathrm{CD}$ and $\mathrm{SU}$ in their free and complexed states are summarized in Table 1.

As expected, the great displacements to the high field of complexed $\beta-\mathrm{CD}$ were observed for H-3 while many hydrogens were less affected. These results proved the occurrence of the interaction between SU and $\beta-C D$ during complexation. The upward displacements of $\mathrm{H}-3$ and $\mathrm{H}-5$ of $\beta-\mathrm{CD}$ indicated that these protons are located near an electron cloud that induced anisotropic magnetic shielding. ${ }^{43}$ Similar results have been described in the literature ${ }^{44}$ as evidence of complexation.

\section{Computational studies}

The thermodynamic data below were calculated using the ONIOM methodology ${ }^{28}$ according to Table 2, in which was possible to identify the energy values of $\Delta \mathrm{G}^{\circ}$ and $\mathrm{K}_{\mathrm{f}}$, which are Gibbs free energy and inclusion complex formation constant, respectively. The results showed that position 1 obtained data similar to the experimental values in free energy of Gibbs than to those corresponding to position 2, all being calculated under vacuum.

According to the data listed in Table 2, the Gibbs free energy $\left(\Delta \mathrm{G}^{\circ}\right)$ of the complexation is negative and has an equilibrium constant greater than 270 . This denotes an exergonic interaction, indicating a spontaneous process. The methods and their respective sets of bases correspond to $1: 1$ stoichiometry, meaning that just one molecule of the drug is included in a $\beta-C D$ cavity, which is the most common type of encapsulation. ${ }^{45}$

Slopes obtained experimentally from the linear regression analysis are less than 1 , in all cases, indicating that both orientations have a stoichiometry of $1: 1 .^{46}$ The thermodynamic parameters of the analyzed inclusion processes, $\mathrm{K}_{\mathrm{f}}$ and $\Delta \mathrm{G}^{\circ}$ can be obtained by means of classical equivalence, as presented in equation 3 :

$\Delta \mathrm{G}^{\circ}=-\mathrm{RT} \ln \mathrm{K}_{\mathrm{f}}$

where $\mathrm{R}$ is the universal gas constant and $\mathrm{T}$ is the temperature. 


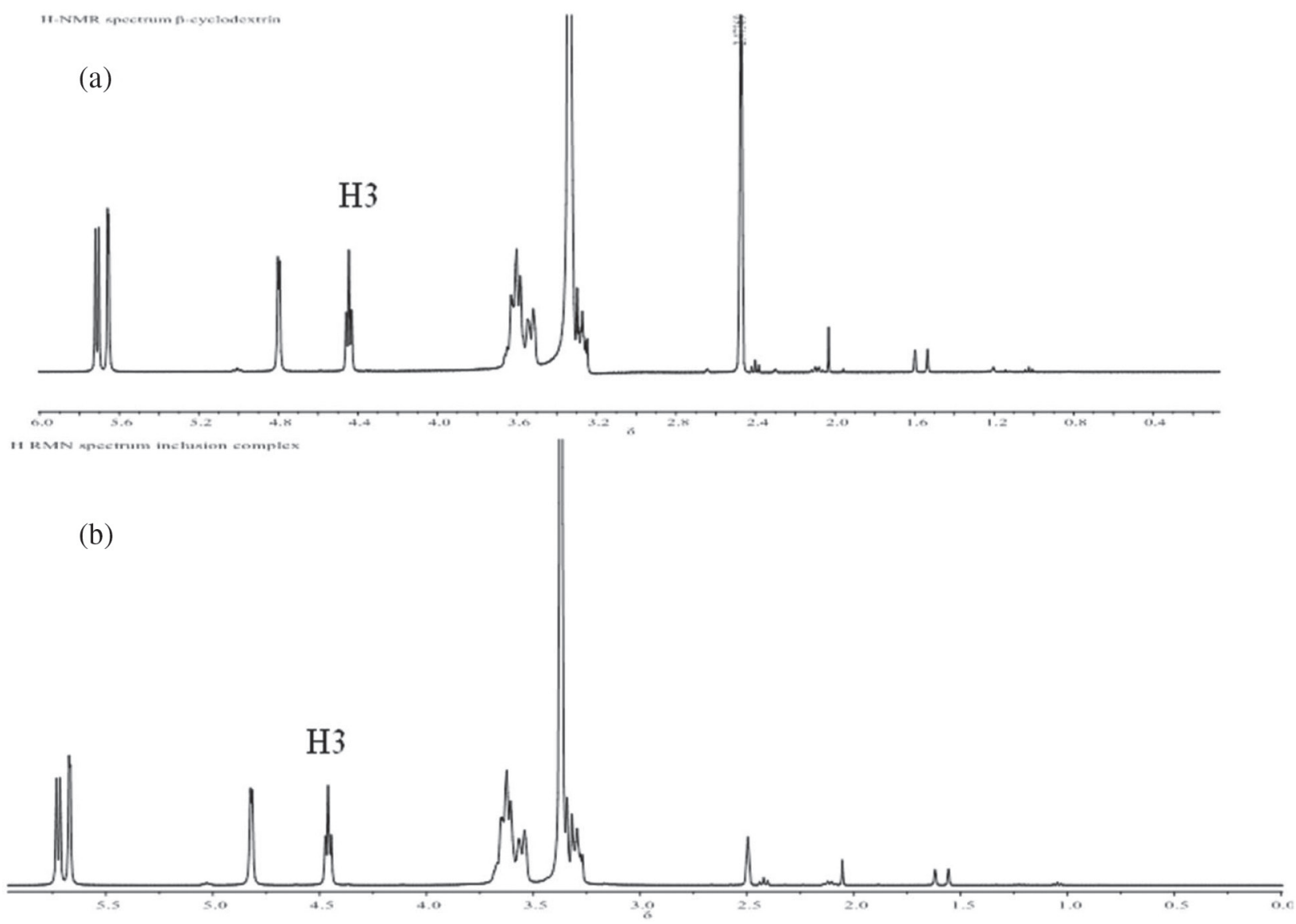

Figure 8. ${ }^{1} \mathrm{H}$ NMR spectra (400 MHz, DMSO- $d_{6}$ ) for $\beta$-cyclodextrin (a) and inclusion complex (b).

Table 1. Chemical shift of ${ }^{1} \mathrm{H}$ corresponding to free and complexed $\beta$-cyclodextrin ( $\beta$-CD)

\begin{tabular}{|c|c|c|c|}
\hline \multirow{2}{*}{${ }^{1} \mathrm{H}$ assignment } & \multicolumn{2}{|c|}{$\delta / \mathrm{ppm}$} & \multirow{2}{*}{$\Delta \delta^{\mathrm{a}} / \mathrm{ppm}$} \\
\hline & $\beta$-CD free & Complex & \\
\hline $\mathrm{H}-1$ & 4.825 & 4.820 & -0.005 \\
\hline $\mathrm{H}-2$ & 3.376 & 3.380 & -0.004 \\
\hline $\mathrm{H}-3$ & 4.470 & 4.460 & -0.010 \\
\hline $\mathrm{H}-4$ & 3.276 & 3.273 & -0.003 \\
\hline H-5 & 3.632 & 3.628 & -0.004 \\
\hline $\mathrm{H}-6$ & 3.555 & 3.552 & -0.003 \\
\hline
\end{tabular}

${ }^{\mathrm{a}} \mathrm{A}$ positive sign of $\Delta \delta \mathrm{ppm}$ shows a downfield chemical displacement and a negative sign an upfield chemical displacement $(\Delta \delta=\delta$ complex $-\delta$ free $)$.

Orientation P1 (Figure 9) corresponds to the chain with the largest number of carbon and hydrogen atoms, in which the interactions of van der Waals will be seen inside the cyclodextrin cavity, that are responsible for the formation of sulcatone: $\beta-C D$ complex, the cyclodextrin cavity. The interactions of van der Waals play an important role in the stabilization of the inclusion complex, since they are weaker attraction forces. ${ }^{28}$

The association constants between drug and CDs are reported in the range of $50-20000 \mathrm{M}^{-1},{ }^{18,37}$ because below that, no stable inclusion complexes are formed. ${ }^{37}$ Changes in thermodynamic parameters that compose the complex formation are phenomena that result in van der Waals energy changes, hydrogen bonds and hydrophobic interactions between drugs and CDs. ${ }^{19}$

The calculated Gibbs free energy values (Table 2) were all negative indicating that the complexations were spontaneous. In relation to the most negative values of Gibbs free energy being more significant for the P1 position, it denotes more adhesion of the aliphatic chain of sulcatone, in addition to the interactions that are hydrophobic within the cavity that confers more stability to the complex structure.

The $\mathrm{K}_{\mathrm{f}}$ constant between drug and cyclodextrin, according to Table 2 , shows higher values when the drug is in orientation P1. This denotes greater fixation of this drug with the CD cavity, because values below $50 \mathrm{M}^{-1}$, ${ }^{46}$ cannot keep the drug inside the cavity for a long time, making complexion difficult.

\section{Hypotensive and vasorelaxant effect of SU and SU- $\beta-C D$}

This present study shows, for the first time, the hypotensive and vasodilator effects of SU in normotensive 


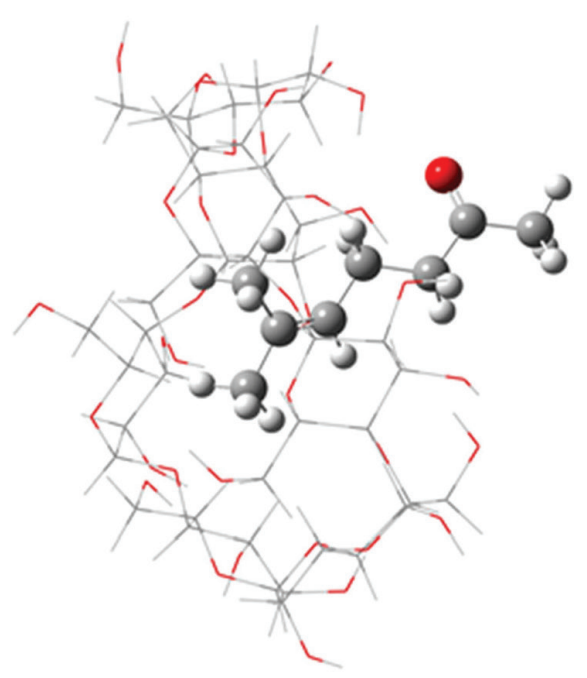

Orientation P1

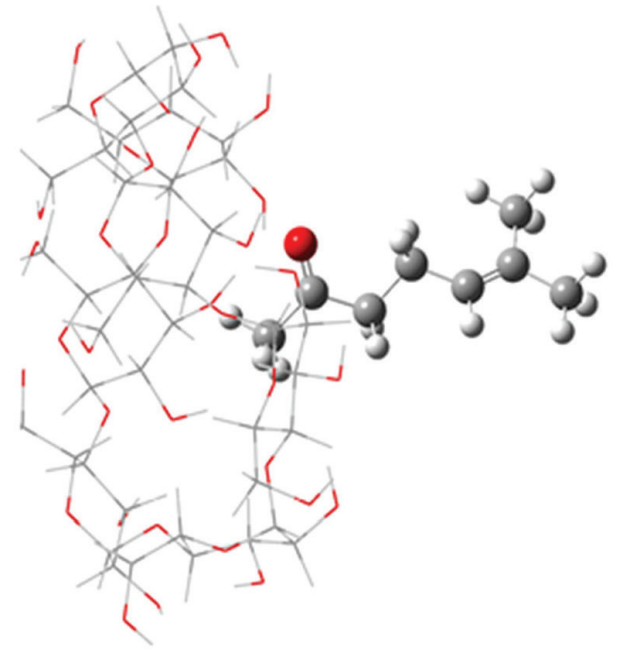

Orientation P2

Figure 9. Orientations P1 and P2 correspond to the encapsulation of hydrophobic and hydrophilic part of the SU molecule in the wider part of the $\beta$-CD cavity.

Table 2. Gibbs energy values $\left(\Delta \mathrm{G}^{\circ}\right)$ in drug orientations 1 and 2 , calculated at $298 \mathrm{~K}$ and $1 \mathrm{~atm}$

\begin{tabular}{lccc}
\hline Method & Orientation & $\Delta \mathrm{G}^{\circ} /\left(\mathrm{kcal} \mathrm{mol}^{-1}\right)$ & $\mathrm{K}_{\mathrm{f}} /\left(\mathrm{mol} \mathrm{L}^{-1}\right)$ \\
\hline \multirow{2}{*}{ 6-31g(d)/PM6 } & $\mathrm{P} 1$ & -3.86 & 680.90 \\
& $\mathrm{P} 2$ & -1.59 & 14.83 \\
\hline \multirow{2}{*}{ 6-31+g(d)/PM6 } & $\mathrm{P} 1$ & -3.33 & 274.12 \\
& $\mathrm{P} 2$ & -2.46 & 63.56 \\
\hline \multirow{2}{*}{$6-31+\mathrm{g}(\mathrm{d}, \mathrm{p}) / \mathrm{PM6}$} & $\mathrm{P} 1$ & -3.19 & 218.79 \\
\hline \multirow{2}{*}{$6-311 \mathrm{~g}(\mathrm{~d}) / \mathrm{PM} 6$} & $\mathrm{P} 2$ & -2.15 & 37.78 \\
\hline \multirow{2}{*}{ 6-311+g(d)/PM6 } & P1 & -3.84 & 651.27 \\
& $\mathrm{P} 2$ & -1.58 & 14.44 \\
\hline
\end{tabular}

$\mathrm{K}_{\mathrm{f}}$ : formation constant.

Wistar rats. Figure 10 shows the vasorelaxant effect of SU over the phenylephrine-induced tonic contractions in the rat aorta, where it can be observed that SU shows concentration-dependent and vascular endotheliumindependent vasorelaxation. This response denies the action of SU over the activation of the endothelial cells and release of endothelium-derived relaxant factors, showing that $\mathrm{SU}$ can act directly upon the smooth vascular muscle.

The respective $\mathrm{pD} 2$ and maximum effectiveness $($ Emax\%) values were $2.19 \pm 0.07$ and $98.12 \pm 5.65 \%$ for endothelium-intact, and $2.29 \pm 0.04$ and $98.02 \pm 4.25 \%$ for endothelium-denuded rings. Phenylephrine is an adrenergic agonist that leads to contraction due to the release of calcium from the intracellular stores sensitive to inositol triphosphate (IP3). It also influences upon the calcium inflow through the CaV-L (long-acting

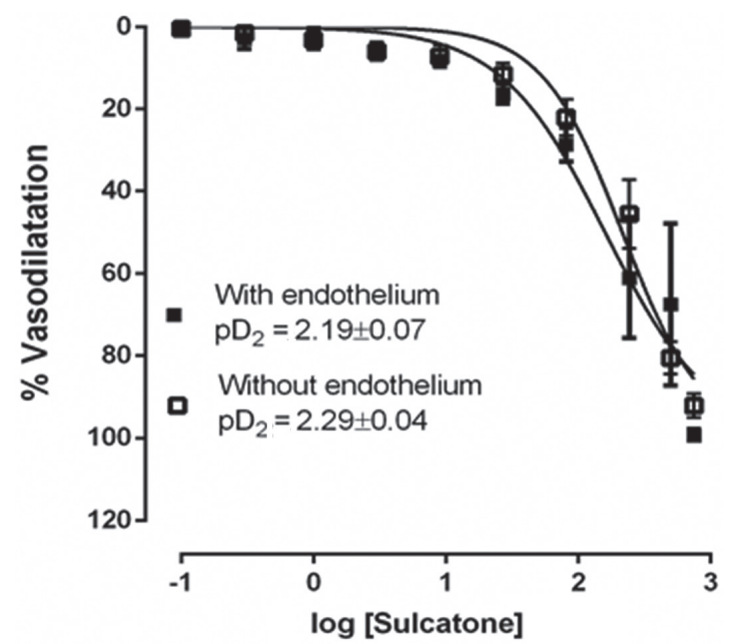

Figure 10. The relaxing effect of sulcatone of rats isolated from endothelium ( $\square$ ) and without endothelium ( $\square$ ) pre-contracted with phenylephrine $\left(10^{-6} \mathrm{M}\right)$. The points represent the mean \pm SEM of the relaxing effect expressed as a percentage.

voltage-dependent channels of the electric current produced by calcium input into the cell) channels of the plasmatic membrane. ${ }^{47-50}$ Thus, it can be inferred that $\mathrm{SU}$ induces relaxation of the aorta by inhibiting the calcium mobilization from the intracellular stores and the inflow of this ion via calcium channels of the plasmatic membrane. According to literature, ${ }^{48,51}$ in the smooth vascular muscle, the increase in intracellular calcium leads to the vasoconstriction mechanism. Thus, natural or synthetic substances that promote the calcium influx inhibition are promising tools for the therapeutics of cardiovascular diseases like arterial hypertension. In this study, the baseline values of MAP and heart rate (HR) were $118 \pm 3 \mathrm{mmHg}$ and $356 \pm 15$ beats $\mathrm{min}^{-1}$, respectively $(n=6)$. The administration of $S U$ at doses 
of $12.5,25$ and $50 \mathrm{mg} \mathrm{kg}^{-1}$ i.v. induced hypotension by $-13.57 \pm 1.09,-27.5 \pm 4.48,-41.51 \pm 1.20 \mathrm{mmHg}$, respectively. This effect was accompanied by tachycardia response in doses of 12.5 and $25 \mathrm{mg} \mathrm{kg}^{-1}$ for $\mathrm{SU}$ $\left(9.48 \pm 2.83\right.$ and $3.52 \pm 2.65$ beats $\mathrm{min}^{-1}$, respectively) and bradycardia effect in the highest dose of $50 \mathrm{mg} \mathrm{kg}^{-1}$ $\left(-64.36 \pm 6.63\right.$ beats $\left.\mathrm{min}^{-1}\right)$ see Figures $11 \mathrm{a}$ and $11 \mathrm{~b}$. The duration of the SU effect on the mean arterial pressure and heart rate was approximately $20 \mathrm{~s}$.

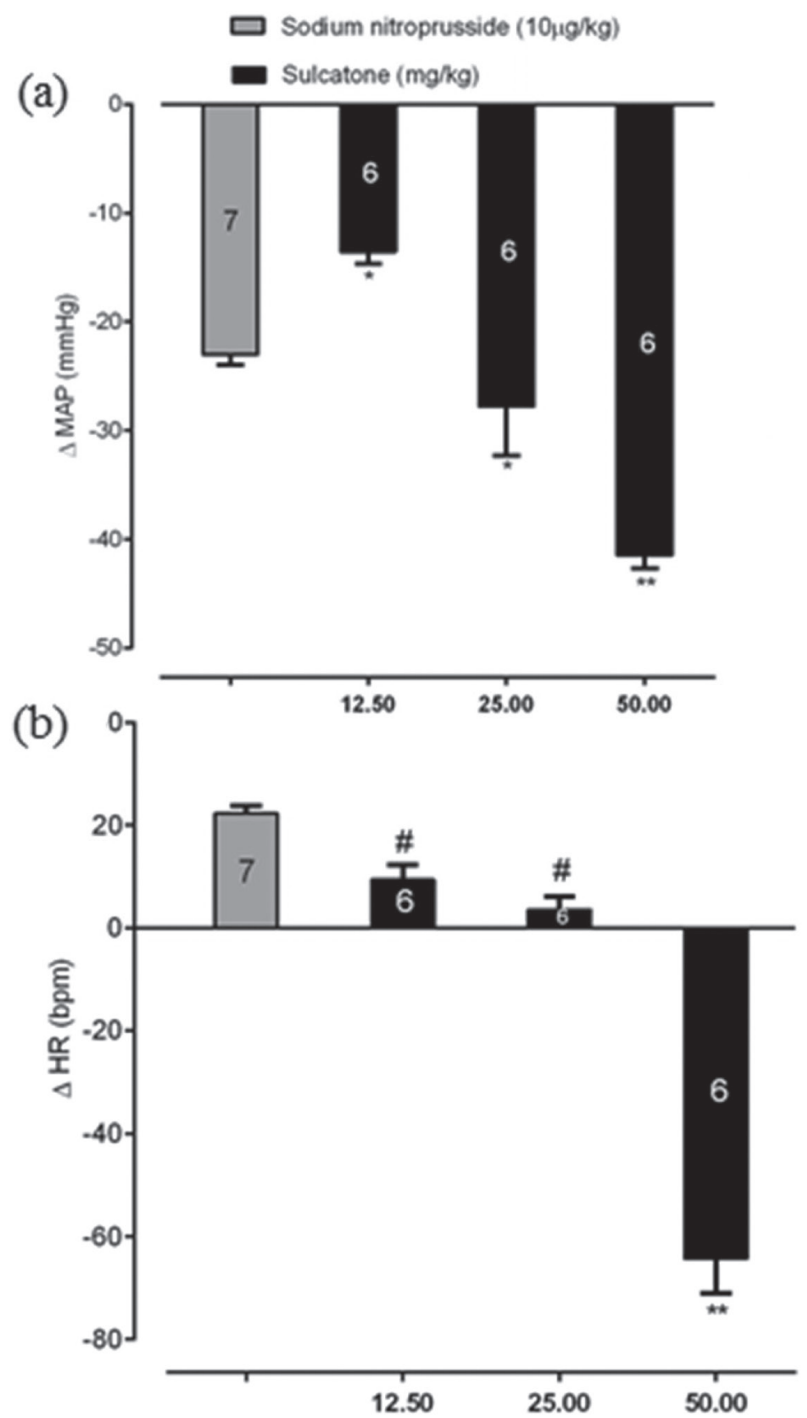

Figure 11. Effect of SU on mean arterial pressure (a) and heart rate (b) in non-anesthetized rats and positive control SNP $\left(10 \mu \mathrm{g} \mathrm{kg}^{-1}\right.$, i.v.). Values are mean \pm SEM of 6-7 experiments. (a) $* p<0.05 v s$. SU $\left(12.5 \mathrm{mg} \mathrm{kg}^{-1}\right)$, $* * p<0.05$ vs. SU $\left(50 \mathrm{mg} \mathrm{kg}^{-1}\right)$; (b) ${ }^{\#} p<0.05$ vs. SNP, **p $<0.05$ vs. SU (12.5 and $25 \mathrm{mg} \mathrm{kg}^{-1}$ ). Student's $t$-test.

The present study therefore sought to investigate the cardiovascular response to SU, a vasorelaxant compound. Both functional and structural modifications of blood vessels have been associated with hypertension. ${ }^{52}$ The mechanism that controls blood pressure involves complex processes that integrate the systems with multiple regulations, particularly hormonal and renal reflex, as well as vascular tonus. ${ }^{47,48}$ In this study, the intravenous administration of SU reduced the arterial pressure at all doses, however, heart rate increased at the lowest doses and decreased at the highest dose. The arterial pressure was obtained by means of the product of the cardiac output and the peripheral vascular resistance. ${ }^{53}$ Hence, the effect of SU can be related to the effect of sulcatone over the vascular resistance; also, the factors that act directly over the cardiac muscle can promote bradycardia and reflex action leading to tachycardia. Studies have shown that substances acting over the muscarinic receptors lead to bradycardia, while those acting in a reflex way induce to tachycardia. However, the data shown herein still do not allow these mechanisms to be stated.

Complexation with $\beta$-cyclodextrin $(\beta-\mathrm{CD})$ can result in increased wettability and/or accentuated reduction in crystal size. Also, an accentuated increase in solubility occurs in the guest molecules in water. ${ }^{54}$ Cyclodextrins can enhance the aqueous solubility of lipophilic drugs without changing their intrinsic ability to permeate biological membranes. ${ }^{55}$ Furthermore, they are considered as nontoxic at low to moderate oral dosages. ${ }^{56,57}$

The $\beta$-CD complexes have been widely used as formulations for the incorporation of natural substances that favor the delivery in biological systems, thus being employed in several areas within pharmacology. In this study, it is proposed the use of a $\beta$-CD inclusion complex to the sulcatone natural product (SU) in a pre-clinical study in the cardiovascular system of rats. Recently, a study has been published ${ }^{57}$ with the antihypertensive potential of the natural products linalool and linalool complexed with $\beta$-cyclodextrin. It was observed that sulcatone $\left(100 \mathrm{mg} \mathrm{kg}^{-1}\right)$ in its free form administered via oral route was efficient in lowering the mean arterial pressure of the animals in a 210-min time (MAP $=-12.23 \pm 1.23 \mathrm{mmHg}$ ). On the other hand, the SU- $\beta-C D$ inclusion complex (100 $\mathrm{mg} \mathrm{kg}^{-1}$ ) increased the SU efficiency in the reduction of the arterial pressure as shown by the values $(\mathrm{MAP}=-20.16 \pm 1.35 \mathrm{mmHg})$ at the same observed time (Figure 12). It is worth mentioning that in $100 \mathrm{mg}$ of inclusion complex it has only $3.7 \mathrm{mg}$ of SU, showing that the SU- $\beta-C D$ complex potentiated the SU response over the arterial pressure.

This result is promising because cyclodextrin probably increases the bioavailability of SU, showing a great pharmacological potential of the SU- $\beta-C D$ complex, making it a promising tool to be used in the future therapeutics of cardiovascular diseases. 


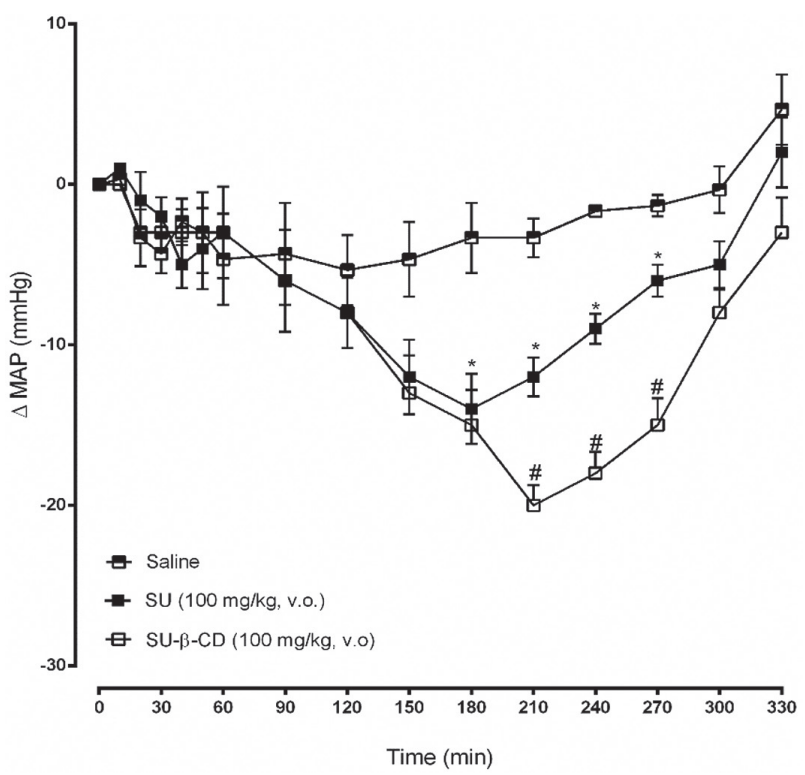

Figure 12. Effect of $100 \mathrm{mg} \mathrm{kg}^{-1}$ dose of SU and SU- $\beta-C D$, orally administered on the mean arterial pressure in rats. All results are expressed as mean \pm SEM of at least three experiments. $* p<0.05 v s$. saline and ${ }^{\#} p<0.05 v s$. SU. The significance of differences between means was assessed by one-way ANOVA followed by a post-hoc Tukey's test.

\section{Conclusions}

In summary, the preparation of the sulcatone inclusion complex in $\beta-C D$ by spray drying has been confirmed by means of DSC, TGA, XRD, FTIR, ${ }^{1} \mathrm{H}$ NMR experimental techniques and computational calculations using the ONIOM model. It was possible to observe by means of a controlled release study the increase of the thermal stability of the complexed sulcatone in relation to its free form, which was confirmed by the negative results of Gibbs free energies. The cardiovascular activity of sulcatone was evaluated by in vivo and in vitro biological assays. It was observed that sulcatone presents a hypotensive and vasorelaxant action in its free form and a pronounced increase in hypotension in its complexed $\beta$-CD form.

\section{Acknowledgments}

The authors are thankful to the Brazilian Agencies CAPES and FAPEPI for financial support, PETROBRAS (by the infrastructure assigned to our laboratory (LAGO)), Labonathus Biotecnologia Internacional (for providing $\beta$-cyclodextrin), as well as Boris Timah for grammatical revision.

\section{Author Contributions}

This work was developed by $\mathrm{PhD}$ student Ivan S. Silva, under the guidance of Professor Sidney G. de Lima, participating in all stages of the work and writing the article. Sulcatone was offered by Professor Péricles B. Alves and the inclusion complex formed and characterized by the authors working in the Organic Geochemistry laboratory (Ivan S. Silva, Eduardo L. Feitosa, Raiane M. Silva, Márcio S. Rocha, Samuel A. A. de Sousa, Sidney G. de Lima). The computational calculations were performed by Francisco I. da Silva, Francisco C. A. Lima, Samuel A. A. de Sousa and Ana Maria S. Costa. Márcio E. P. Santos and Aldeídia P. Oliveira were responsible of the biological activity.

\section{References}

1. Rosamond, W.; Flegal, K.; Furie, K.; Go, A.; Greenlund, K.; Haase, N.; Hailpern, S. M.; Ho, M.; Howard, V.; Kissela, B.; Kittner, S.; Lloyd-Jones, D.; McDermott, M.; Meigs, J.; Moy, C.; Nichol, G.; O’Donnell, C.; Roger, V.; Sorlie, P.; Steinberger, J.; Thom, T.; Wilson, M.; Hong, Y.; Circulation 2008, 117, e25.

2. Singh, R.; Bharti, N.; Madan, J.; Hiremath, S. N.; J. Pharm. Sci. Technol. 2010, 2, 171.

3. Lefkowitz, R. J.; Willerson, J. T.; J. Am. Med. Assoc. 2001, 285, 581.

4. Szejtli, J.; Chem. Rev. 1998, 98, 1743.

5. Biala, A.; Finckenberg, P.; Korpi, A.; Loytainen, M.; Martonen, E.; Levijoki, J.; Mervaala, E.; J. Physiol. Pharmacol. 2011, 62, 275.

6. Del Valle, J. M.; J. Supercrit. Fluids 2015, 96, 180.

7. Del Rio, D.; Costa, L. G.; Lean, M. E. J.; Crozier, A.; Nutr., Metab. Cardiovasc. Dis. 2010, 20, 1.

8. Venturini, C. D. G.; Nicolini, J.; Machado, C.; Machado, V. G.; Quim. Nova 2008, 31, 360.

9. Ioele, G.; De Luca, M.; Ragno, G.; Future Med. Chem. 2014, 6,35 .

10. Loftsson, T.; Brewster, M. E.; J. Pharm. Sci. 1996, 85, 1017.

11. Del Valle, J. M.; De La Fuente, J. C.; J. Food Eng. 2005, 67, 35.

12. McBride, C. S.; Baier, F.; Omondi, A. B.; Spitzer, S. A.; Lutomiah, J.; Sang, R.; Ignell, R.; Leslie, B. Vosshall, L. B.; Nature 2014, 13, 222.

13. Ferreira, H. V.; Rocha, L. C.; Severino, R. P.; Viana, R. B.; da Silva, A. B. F.; Porto, A. L. M.; J. Iran. Chem. Soc. 2010, 7, 883.

14. Ciobanu, A.; Mallard, I.; Landy, D.; Brabie, G.; Nistor, D.; Fourmentin, S.; Carbohydr. Polym. 2012, 87, 1963.

15. Blach, P.; Fourmentin, S.; Landy, D.; Cazier, F.; Surpateanu, G.; Chemosphere 2008, 70, 374.

16. Fourmentin, S.; Ciobanu, A.; Landy, D.; Wenz, G.; Beilstein J. Org. Chem. 2013, 9, 1185.

17. Hundre, S. Y.; Karthik, P.; Anandharamakrishnan, C.; Food Chem. 2015, 174, 16. 
18. Wu, Y.; Zou, L.; Mao, J.; Huang, J.; Liu, S.; Carbohydr. Polym. 2014, 102, 497.

19. Haloci, E.; Toska, V.; Shkreli, R.; Goci, E.; Vertuani, S.; Manfredini, S.; J. Inclusion Phenom. Macrocyclic Chem. 2014, 80, 147.

20. Frisch, M. J.; Trucks, G. W.; Schlegel, H. B.; Scuseria, G. E.; Robb, M. A.; Cheeseman, J. R.; Scalmani, G.; Barone, V.; Mennucci, B.; Petersson, G. A.; Nakatsuji, H.; Caricato, M.; Li, X.; Hratchian, H. P.; Izmaylov, A. F.; Bloino, J.; Zheng, G.; Sonnenberg, J. L.; Hada, M.; Ehara, M.; Toyota, K.; Fukuda, R.; Hasegawa, J.; Ishida, M.; Nakajima, T.; Honda, Y.; Kitao, O.; Nakai, H.; Vreven, T.; Montgomery Jr., J. A.; Peralta, J. E.; Ogliaro, F.; Bearpark, M.; Heyd, J. J.; Brothers, E.; Kudin, K. N.; Staroverov, V. N.; Kobayashi, R.; Normand, J.; Raghavachari, K.; Rendell, A.; Burant, J. C.; Iyengar, S. S.; Tomasi, J.; Cossi, M.; Rega, N.; Millam, J. M.; Klene, M.; Knox, J. E.; Cross, J. B.; Bakken, V.; Adamo, C.; Jaramillo, J.; Gomperts, R.; Stratmann, R. E.; Yazyev, O.; Austin, A. J.; Cammi, R.; Pomelli, C.; Ochterski, J. W.; Martin, R. L.; Morokuma, K.; Zakrzewski, V. G.; Voth, G. A.; Salvador, P.; Dannenberg, J. J.; Dapprich, S.; Daniels, A. D.; Farkas, Ö.; Foresman, J. B.; Ortiz, J. V.; Cioslowski, J.; Fox, D. J.; Gaussian 09 Revision D.01; Gaussian Inc., Wallingford, CT, 2013.

21. Pettersen, E. F.; Goddard, T. D.; Huang, C. C.; Couch, G. S.; Greenblatt, D. M.; Meng, E. C.; Ferrin, T. E.; J. Comput. Chem. 2004, 25, 13.

22. Mire, L. W.; Wheeler, S. D.; Wagenseller, E.; Marynick, D. S.; Inorg. Chem. 1998, 37, 3099.

23. Nazarparvar, E.; Zahedi, M.; Klein, E.; J. Org. Chem. 2012, 77, 10093.

24. Ramachandran, K. I.; Deepa, G.; Namboori, K.; Computational Chemistry and Molecular Modeling; Springer-Verlag: Berlin, Heidelberg, Germany, 2008.

25. Binkley, J. S.; Pople, J. A.; Hehre, W. J.; J. Am. Chem. Soc. 1980, 102, 939.

26. Ditchfield, R.; Hehre, W. J.; Pople, J. A.; J. Chem. Phys. 1971, 54,724 .

27. Francl, M. M.; Pietro, W. J.; Hehre, W. J.; Binkley, J. S.; Gordon, M. S.; DeFrees, D. J.; Pople, J. A.; J. Chem. Phys. 1982, 77, 3654.

28. Dapprich, S.; Komáromi, I.; Byun, K. S.; Morokuma, K.; Frisch, M. J.; J. Mol. Struct.: THEOCHEM 1999, 461-462, 1.

29. Humbel, S.; Sieber, S.; Morokuma, K.; J. Chem. Phys. 1996, 105, 1959.

30. Mennucci, B.; Cammi, R.; Continuum Solvation Models in Chemical Physics: From Theory to Applications; John Wiley \& Sons Ltd.: Chippenham, Wiltshire, Great Britain, 2007.

31. Dennington, R.; Keith, T.; Millam, J.; GaussView, version 5; Semichem Inc., Shawnee Mission, USA, 2009.

32. Conselho Federal de Medicina Veterinária (CFMV); Resolução No. 1000, de 11 de Maio de 2012; Dispõe sobre Procedimentos e Métodos de Eutanásia em Animais e dá outras Providências; Diário Oficial da União, Brasília, p. 124. Available at http:// portal.cfmv.gov.br/lei/index/id/326, accessed in December 2019.

33. Furchgott, R. F.; Zawadzki, J. V.; Nature 1980, 288, 373.

34. Oliveira, E. J.; Medeiros, I. A.; Mukherjee, R.; Phytomedicine 1996, $3,45$.

35. Santos, M. E. P.; Moura, L. H. P.; Mendes, M. B.; Arcanjo, D. D. R.; Monção, N. B. N.; Araújo, B. Q.; Lopes, J. A. D.; SilvaFilho, J. C.; Fernandes, R. M.; Oliveira, R. C. M.; Citó, A. M. G. L.; Oliveira, A. P.; J. Ethnopharmacol. 2015, 164, 120.

36. Graph Pad Software, Inc.; SanDiego, CA, USA.

37. Veiga, F.; Pecorelli, C.; Ribeiro, L.; As Ciclodextrinas em Tecnologia Farmacêutica, vol. 1, $1^{\text {st }}$ ed.; Minerva Coimbra: Coimbra, Portugal, 2006.

38. Santos, J. V.; Moura, T. F. A.; Raffin, F. N.; Lat. Am. J. Pharm. 2003, 22, 327.

39. Zingone, G.; Rubessa, F.; Int. J. Pharm. 2005, 291, 3.

40. Cabral-Marques, H. M.; Morais, J. A.; Rev. Port. Farm. 1991, 41,5 .

41. Marques, H. M. C.; Hadgraft, J.; Kellaway, I. W.; Int. J. Pharm. 1990, 63, 259.

42. Kfoury, M.; Auezova, L.; Ruellan, S.; Greige-Gerges, H.; Fourmentin, S.; Carbohydr. Polym. 2015, 118, 156.

43. Nakamura, A.; Sato, S.; Hamasaki, K.; Ueno, A.; Toda, F.; J. Phys. Chem. 1995, 99, 10952.

44. Sun, Q.; Tang, P.; Zhao, L.; Pu, H.; Zhai, Y.; Li, H.; Carbohydr. Polym. 2018, 194, 294.

45. Sancho, M. I.; Andujar, S.; Porasso, R. D.; Enriz, R. D.; J. Phys. Chem. B 2016, 120, 3000.

46. Lyra, M. A. M.; Soares-Sobrinho, J. L.; Figueiredo, R. C. B. Q.; Sandes, J. M.; Lima, Á. A. N.; Tenório, R. P.; Fontes, D. A. F.; Santos, F. L. A.; Rolim, L. A.; Rolim-Neto, P. J.; J. Inclusion Phenom. Macrocyclic Chem. 2012, 73, 397.

47. Dellis, O.; Dedos, S. G.; Tovey, S. C.; Taufiq-Ur-Rahman; Dubel, S. J.; Taylor, C. W.; Science 2006, 313, 229.

48. Xia, M.; Qian, L.; Zhou, X.; Gao, Q.; Bruce, I. C.; Xia, Q.; J. Ethnopharmacol. 2008, 120, 442.

49. Catterall, W. A.; Perez-Reyes, S. E.; Snutch, T. P.; Striessnig, J.; Pharmacol. Rev. 2005, 57, 411.

50. Castro, M. M.; Tanus-Santos, J. E.; Gerlach, R. F.; Pharmacol. Res. 2011, 64, 567.

51. Coffman, T. M.; Crowley, S. D.; Hypertension 2018, 51, 811.

52. Sanjuliani, A. F.; Rev. SOCERJ 2002, 15, 210.

53. Morais, I. C. P. S.; Moura, I. J. L.; Sabino, C. K. B.; Nicolau, L. A. D.; Souza, F. M.; Silva-Filho, J. C.; Oliveira, R. C. M.; Medeiros, J. V. R.; Lima, S. G.; Oliveira, A. P.; J. Med. Food 2019, 22, 248.

54. Mendes, M. B.; Silva-Filho, J. C.; Sabino, C. K. B.; Arcanjo, D. D. R.; Sousa, C. M. M.; Costa, I. C. G.; Chaves, M. H.; Oliveira, R. C. M.; Oliveira, A. P.; J. Med. Food 2014, 17, 1079. 
55. Irie, T.; Uekama, K.; J. Pharm. Sci. 1997, 86, 147.

56. Camargo, S. B.; Simões, L. O.; Medeiros, C. F. A.; Jesus, A. M.; Fregoneze, J. B.; Evangelista, A.; Villarreal, C. F.; Araújo, A. A. S.; Quintans-Júnior, L. J.; Silva, D. F.; Biochem. Pharmacol. 2018, 151, 38 .
57. Rasheed, A.; Kumar, A. C. K.; Sravanthi, V. V. N. S. S.; Sci. Pharm. 2008, 76, 567.
Submitted: September 16, 2019 Published online: December 12, 2019 